\title{
REGULACIÓN Y FOMENTO DE LOS REGÍMENES \\ DE CALIDAD DE PRODUCTOS AGRARIOS Y \\ ALIMENTICIOS: SU IMPACTO EN EL DESARROLLO \\ RURAL DE LA UNIÓN EUROPEA Y ESPAÑA
}

\author{
Pablo Amat Llombart \\ Profesor Titular de Derecho Civil \\ Universidad Politécnica de Valencia \\ E-mail: pabamllo@urb.upv.es
}

\begin{abstract}
RESUMEN: La política de desarrollo rural comunitaria incluye entre sus medidas el impulso a los regímenes de calidad de las producciones agroalimentarias, financiando a nivel de la UE y de los Estados ayudas que faciliten su implantación y consolidación en las explotaciones agrarias. El éxito de tales regímenes de calidad puede coadyuvar a la consecución de los objetivos del desarrollo rural. A tal fin, se debe fomentar un sector agrario más competitivo, rentable e innovador, así como un desarrollo de los territorios rurales sostenible y equilibrado, desde la perspectiva económica, social y medioambiental.
\end{abstract}

Palabras clave: desarrollo rural; calidad alimentaria; sostenibilidad.

ABSTRACT: The rural development policy of the EU includes among its measures the promotion of quality regimes for agri-food productions, financing at EU and State level aids that facilitate their implementation and consolidation in agricultural holdings. The success of such quality schemes can contribute to the achievement of rural development goals. To this end, a more competitive, profitable and innovative agricultural sector should be promoted, as well as a sustainable and balanced development of rural areas, from an economic, social and environmental perspective.

Key words: rural development; Food quality; sustainability.

\footnotetext{
Sumario: I. Introducción. II. La Política de Desarrollo Rural de la Unión Europea en El Marco de la Pac: Fomento de la Calidad De Productos Agroalimentarios. 2.1. El segundo pilar de la PaC: el Reglamento 1305/2013 sobre ayudas al desarrollo rural y su apuesta por los regímenes de calidad agroalimentaria. Aproximación. 2.2. Los regímenes de calidad de productos agrícolas y alimenticios en la misión y objetivos del Reglamento 1305/2013 de desarrollo rural. 2.3. Implementación de medidas y ayudas de desarrollo rural financiadas por el FEADER vinculadas a la calidad de la producción agroalimentaria europea. III. RÉGIMEN LEGAL DE LA CALIDAD AGROALIMENTARIA DIFERENCIADA EN ESPAÑA Y SU VINCULACIÓN AL DESARROLLO RURAL Y TERRITORIAL. 3.1. Calidad alimentaria y calidad diferenciada: distinción. 3.2. Regulación de las DOP y las IGP: incidencia en el desarrollo rural. 3.3. Regulación de la producción ecológica: gestión sostenible de los recursos naturales y acción por el clima. IV. Conclusiones. V. BibLiografía.
} 


\section{INTRODUCCIÓN}

El presente trabajo profundiza en uno de los aspectos característicos de lo que se ha venido llamando la «nueva ruralidad», como es la progresiva especialización de determinadas zonas y espacios rurales en producción de calidad y en el uso de marcas distintivas. Este tipo de estrategia de creación de valor añadido en los productos agrarios y alimentarios constituye una de las líneas prioritarias de los Programas de Desarrollo Rural aprobados e implementados en la Unión Europea desde fines del siglo XX y lo que llevamos del siglo XXI. El paradigma consistente en otorgar valor y visibilidad a la producción agroalimentaria desde una perspectiva de marca o distinción en el mercado, constituye una forma más de desarrollar el enfoque territorial que pretende incorporar la Política Agrícola Común (PAC) ${ }^{1}$, así como las políticas rurales de algunos Estados miembros de la UE como España. De esa idea surge un nuevo concepto de territorio rural, que de mero soporte de actividades se convierte en un recurso para el desarrollo ${ }^{2}$.

La incesante proliferación de denominaciones, signos distintivos y marcas de calidad de productos agroalimentarios denota la profunda transformación con que los espacios rurales pretenden avanzar en el siglo XXI. En determinados territorios se podría incluso hablar de una transición que camina desde una producción agraria poco imaginativa y escasamente rentable, continuista o basada en monocultivos tradicionales, hacia nuevos modelos de diversificación productiva, que buscan en el medio rural una economía de valor capaz de responder a los nuevos retos de la globalización, a las exigencias de los mercados y los hábitos de los consumidores.

En efecto, entre los distintos regímenes de calidad de los productos agrarios y alimenticios, en Europa destacan por su implantación, presencia y prestigio las denominaciones de origen protegidas (DOP), como por ejemplo en España las vinculadas a los vinos, entre otra infinidad de productos, las indicaciones geográficas protegidas (IGP), las especialidades tradicionales garantizadas (ETG) y los productos de la agricultura ecológica (AE), principalmente ${ }^{3}$.

El principal objetivo de este trabajo se focaliza en poner en valor y analizar la evidente relación entre los diferentes sistemas de calidad vinculados a la producción agroalimentaria y la Política Agrícola Común de la UE, especialmente su conexión con el segundo pilar de la PAC (política de desarrollo rural) y su específica aplicación en los Estados miembros como España. En ese sentido, no en vano resulta destacable el progresivo apoyo que los sucesivos Programas de Desarrollo Rural (PDR) -implementados

1 Para una aproximación orientativa general a la esencia jurídica de la PAC, vid. AMAT LLOMBART, P. «Principios jurídicos informadores, orientadores y de aplicación de la Política Agrícola Común Europea 2014-2020», Revista de Derecho Agrario y Alimentario, n'. 72, 2018, pp. 7-30.

2 Sobre esta cuestión vid. AGUILAR CRIADO, E., AMAYA CORCHUELO, S. y LÓPEZ MORENO, I. «Alimentos con calidad: Nuevas estrategias rurales para nuevos consumidores», Arxiu d'etnografia de Catalunya: revista d'antropologia social, $\mathrm{n}^{\circ}$. 16, 2016, pp. 137-152.

3 Véase el completo y actualizado estudio sobre las distintas figuras de protección de productos de calidad agroalimentaria de MILLÁN SALAS, F. «Producción agroalimentaria de calidad: denominaciones de origen e indicaciones geográficas protegidas, especialidades tradicionales garantizadas, producción ecológica e integrada», en Tratado de derecho agrario, Esther Muñiz Espada y Pablo Amat Llombart (Dirs.), La Ley-Wolters Kluver, Madrid, 2017, pp. 611-655. También de este mismo autor vid. «Los regímenes de calidad de los productos agrícolas y alimenticios tras el Reglamento (UE) 1151/2012», Actualidad Civil, nº 10, 2014. Igualmente vid. SÁNCHEZ HERNÁNDEZ, A. «Productos agroalimentarios de calidad y su indicación en España», Campo jurídico: Revista de direito agroambiental e teoria do direito, vol. 3, $\mathrm{n}^{\circ} .1,2015$. 
a nivel nacional- han prestado en favor de la promoción, protección y revitalización de los productos agrícolas tradicionales y regionales, anclados a una producción territorial determinada, geográficamente localizada y basada en técnicas de elaboración específicas y singulares que otorgan al producto final esa calidad distintiva cada vez más apreciada en el mercado y por los consumidores. Ese mayor apoyo institucional, económico y social a los productos agroalimentarios de calidad redundará en el aumento de la capacidad de activación territorial de tales productos, dentro del medio rural en que se elaboran, así como en la generación de beneficios para las comunidades rurales donde se producen, tanto en el ámbito económico, como en el cultural y social.

En otro orden de cosas, la consolidación del impulso y protección de las producciones locales o regionales de calidad se ajusta adecuadamente a los objetivos propios de los proyectos de desarrollo tendentes a diversificar las economías rurales, apoyando iniciativas vinculadas a los valores tangibles e intangibles de la cultura local, capaces de generar externalidades positivas y de contribuir al mantenimiento de la estructura demográfica y de los mercados de trabajo, y con ello al sostenimiento del nivel de vida digno de las comunidades rurales afectadas.

Asimismo, los sistemas de producción agraria de calidad deberían vincularse estrechamente con la introducción y consolidación de buenas prácticas agrícolas y medioambientales, a fin de dar a luz sistemas productivos más ecológicos y sostenibles. A tal efecto, deberán ser ejemplo de impactos positivos en la reducción de la contaminación, en el ahorro de recursos hídricos, en la contribución al fomento de la biodiversidad y la reducción de los agentes contaminantes propios de la agricultura intensiva.

Como resultado final, el «nuevo producto agroalimentario» deberá ser el fruto de la adecuada y eficiente combinación entre conocimientos y tecnología tradicionales e innovaciones técnicas modernas. El producto agrario de calidad podrá en valor máximo el discurso de la tradición y su anclaje a un territorio determinado como parte sustancial del marketing comercial, de modo que los elementos consustanciales de una particular ecología, tradición e historia, se incorporen como componentes distintivos de esos productos locales. En suma, el aumento de los signos de calidad agroalimentarios constituye un fenómeno ligado tanto a las nuevas funciones de los espacios rurales como a recientes demandas de los consumidores de las sociedades posindustriales. Así, los productos de calidad se erigen como garantes de seguridad alimentaria, dotados además del valor añadido que le proporciona su vinculación con un territorio concreto.

\section{LA POLÍtiCA DE DESARROLLO RURAL DE LA UNIÓN EUROPEA EN EL MARCO DE LA PAC: FOMENTO DE LA CALIDAD DE PRODUCTOS AGROALIMENTARIOS}

\subsection{El segundo pilar de la PAC: el Reglamento 1305/2013 sobre ayudas al desarrollo rural y su apuesta por los regímenes de calidad agroalimentaria. Aproximación}

La política de desarrollo rural (segundo pilar) viene a acompañar y completar la política de pagos directos y de medidas de mercado de la PAC (primer pilar), contribuyendo así a conseguir los objetivos establecidos en el Tratado de Funcionamiento de la Unión Eu- 
ropea. La norma básica de dicha política la constituye el Reglamento 1305/2013, de 17 de diciembre de 2013, relativo a la ayuda al desarrollo rural a través del Fondo Europeo Agrícola de Desarrollo Rural (FEADER) ${ }^{4}$.

Ye en el Preámbulo del Reglamento 1305/2013 (Considerando 14), se pone de manifiesto la relevancia que el fomento de los sistemas de calidad de los productos agrícolas y alimentarios puede suponer para el desarrollo rural de Europa: «Los regímenes de calidad de la Unión o nacionales incluidos los regímenes de certificación de explotaciones agrícolas para los productos agrícolas y los alimentos ofrecen a los consumidores garantías sobre la calidad y características del producto o sobre el proceso de producción utilizado como resultado de la participación de los agricultores en estos regímenes ${ }^{5}$, ofrecen un valor añadido a los productos y mejoran sus posibilidades de comercialización. Por lo tanto, debe animarse a los agricultores y agrupaciones de agricultores a participar en estos regímenes».

Continúa el propio Considerando 14 aludiendo a determinadas condiciones subjetivas, objetivas y temporales para el acceso a dicha ayuda de desarrollo rural vinculada a la calidad del producto agrario: «Para garantizar un uso eficaz de los recursos presupuestarios del FEADER, la ayuda se deberá limitar a los agricultores activos en el sentido del artículo 9 del Reglamento $n^{\circ}$. 1307/2013. Dado que, en el momento de su entrada en este tipo de regímenes y en los primeros años de participación, los costes y las obligaciones suplementarios impuestos a los agricultores como resultado de su participación no son compensados totalmente por el mercado, se debe conceder ayuda a la participación y esta debe abarcar un período máximo de cinco años ${ }^{6}$. Dadas las características especiales del algodón como producto de explotación, los regímenes de calidad del algodón también deben estar cubiertos. También se deben apoyar las actividades de información y promoción relativas a productos cubiertos por la ayuda a los regímenes de calidad y certificación prevista en el presente Reglamento».

Veamos pues seguidamente la incorporación del impulso a la calidad agroalimentaria en el seno de los objetivos esenciales de la política comunitaria de desarrollo rural, para después proceder a analizar las condiciones, requisitos y alcance de las ayudas específicas a regímenes de calidad concretos, todo ello en el marco del Reglamento $1305 / 2013$.

4 Para mayor información y análisis, vid. AMAT LLOMBART, P. «La política y las ayudas al desarrollo rural en la PAC 2014-2020: Proceso de aplicación en España», en La nueva PAC 2014-2020. Un enfoque desde el derecho agrario, Pablo Amat Llombart y Esther Muñiz Espada (Eds.), Universidad Politécnica de Valencia, Valencia, 2015, pp. 177-228. También de este mismo autor vid. «O segundo pilar da PAC no horizonte de 2020. Missao, objetivos e prioridades do desenvolvimento rural no ambito do regulamento 1305/2013», en A lei agraria nova, Edit. Juruá, Brasil, 2017, pp. 137-155. Asimismo, vid. DE LA CUESTA SÁENZ, J.M. «La regulación del desarrollo rural en España», Revista de Derecho Agrario y Alimentario, nº. 72, 2018, pp. 31-47.

5 Los consumidores constituyen una pieza clave en el éxito comercial y social de los productos protegidos por un signo distintivo de calidad agroalimentaria. De ahí la relevancia de conocer ese nicho de demanda, sus intereses y el potencial de desarrollo. Al respecto vid. AMAT LLOMBART, P. «Indicaciones de calidad en productos agrícolas y alimenticios e intereses de los consumidores», en Le indicazioni di qualità degli alimenti. Diritto internazionale ed europeo, Giuffrè, Milán, 2009, pp. 100-112.

6 Si bien debe tenerse en cuenta que una posterior modificación del R. 1305/2013 (operada por el Reglamento (UE) 2017/2393, de 13 de diciembre de 2017), ha permitido que los productores que accedieron a ayudas durante los primeros cinco años de aplicación del sistema, puedan seguir recibiéndolas cinco años más, según dispone el reformado artículo 16.1 de dicho Reglamento. 


\subsection{Los regímenes de calidad de productos agrícolas y alimenticios en la misión y objetivos del Reglamento 1305/2013 de desarrollo rural}

Ya adentrándonos en el texto articulado del R. 1305/2013, conviene detenerse en el artículo 3 que viene a establecer la «misión» de la política de desarrollo rural de la UE para el periodo de programación y financiero 2013-2020. Según dicho precepto «El FEADER contribuirá a la estrategia Europa 2020 fomentando un desarrollo rural sostenible en toda la Unión como complemento de los demás instrumentos de la PAC, la política de cohesión y la política pesquera común. Contribuirá al desarrollo en la Unión de un sector agrícola más equilibrado desde la óptica territorial y medioambiental, más respetuoso con el clima, más resistente a los cambios climáticos, más competitivo y más innovador. También debe contribuir al desarrollo de los territorios rurales» ${ }^{7}$.

En consonancia con la misión global de las ayudas al desarrollo rural y a fin de lograr su consecución, el artículo 4 del R. 1305/2013 desglosa los tres objetivos esenciales de la política comunitaria de desarrollo rural:

a. Fomentar la competitividad de la agricultura;

b. Garantizar la gestión sostenible de los recursos naturales y la acción por el clima;

c. Lograr un desarrollo territorial equilibrado de las economías y comunidades rurales incluyendo la creación y conservación del empleo.

Ciertamente, la implantación de sistemas jurídicos y agronómicos de reconocimiento de la calidad de productos agroalimentarios en un territorio determinado, incide plenamente en la consecución de los citados objetivos, coadyuvando así a cumplir la misión de la política de desarrollo rural de la UE.

En primer lugar, respecto al aumento de la competitividad de la agricultura, qué duda cabe que los regímenes de calidad agroalimentarios imprimen en el producto final un sello de prestigio, un valor añadido en forma de incremento del precio de comercialización que el consumidor está dispuesto a pagar, en atención a las bondades que atesora el producto protegido por una DOP o una IGP, o elaborado según las normas de la agricultura ecológica. Ello implica un mejor posicionamiento de estas producciones en el mercado y una rentabilidad superior al producto convencional, que debería redundar en beneficio de los actores de la cadena productiva, empezando por el agricultor. En ese sentido, dentro de las medidas que procede introducir para fomentar la mejora en la organización de la cadena alimentaria ${ }^{8}$, se incluye como prioridad la de incrementar la competitividad de los productores primarios integrándolos mejor en la cadena agroalimentaria a través de regímenes de calidad.

7 Acerca del concepto del principio de desarrollo sostenible, abundando en su origen y consolidación a nivel internacional, europeo y nacional, puede consultarse la obra de AMAT LLOMBART, P. y MONFORT PERIS, R. El contrato territorial para el desarrollo sostenible del medio rural, Aranzadi, Cizur Menor, 2016, sobre todo las pp. 15 a 48.

8 Vid. el interesante y completo trabajo de RODRÍGUEZ CACHÓN, T. Relaciones contractuales de la cadena alimentaria. Estudio desde el análisis económico del Derecho, Dykinson, Madrid, 2020. De interés para este artículo, consultar el capítulo preliminar (pp. 23 y ss.), así como las pp. 170 a 172, donde se apuntan medidas para reducir los costes de transacción en la cadena alimentaria, señalando entre otras el fomento de los regímenes de calidad alimentaria. 
Por otra parte, como señala la doctrina -si bien en relación con las DOP aunque resulta extensible a los demás regímenes de calidad-, allí donde esa figura se ha implantado y utilizado normalmente se ha derivado un considerable incremento de la renta económica de los agricultores y/o ganaderos de la concreta zona geográfica, lo que ha favorecido el asentamiento de la población en el medio rural afectado por la denominación de origen. Cuando un producto está amparado en una denominación de origen, la vinculación de ese producto a la indicación geográfica en que consiste la denominación de origen genera, en la mente del potencial consumidor, la idea de unas características y una calidad concretas, debidas a haber sido ese producto fabricado, elaborado, cosechado o extraído en la zona geográfica delimitada por la denominación de origen y, en consecuencia, esa prestación propia de la zona protegida con la denominación de origen cuenta con «un valor añadido dentro del tráfico económico», respecto de otros productos de la misma clase que carecen de la posibilidad de verse amparados de ese modo. La denominación de origen es, pues, una prueba de prestigio y calidad, una evidencia de que determinados productos, especialmente de alimentación, se caracterizan por tener unas características y peculiaridades superiores que los diferencian de esos mismos productos genéricos. Los consumidores reconocen que los vinos, los dulces, los quesos, los jamones, las legumbres, las frutas, etc., de determinadas zonas geográficas que cuentan con una denominación de origen gozan de unas particularidades concretas que los diferencian de esos mismos productos que no son de esa misma zona, y los hacen superiores. Con las denominaciones de origen los productores obtienen una protección legal contra la producción o elaboración de tales productos en otras zonas, aunque se utilicen los mismos ingredientes y procedimientos, lo que les permite influir sobre el precio final de dichos productos; además, la figura de la denominación de origen fomenta la organización del sector productivo y facilita el acceso de los productores tanto a los mercados nacionales como a los internacionales ${ }^{9}$.

En segundo lugar, el objetivo de la sostenibilidad medioambiental y del uso de los recursos naturales queda absolutamente consagrado en determinados regímenes de calidad de la producción agraria, como lo es por definición el sello de la agricultura ecológica.

Así se afirma que la búsqueda de métodos de producción más amigables con el medio ambiente por grupos de productores y consumidores en la Unión Europea, junto con los problemas económicos, ambientales y sociales de la agricultura convencional, ha dado como resultado un mayor impulso a la certificación de los productos agrícolas y en especial a aquellos obtenidos mediante la agricultura ecológica y otros productos de calidad diferenciada ${ }^{10}$.

En efecto, la producción ecológica es un sistema general de gestión agrícola y producción de alimentos que combina las mejores prácticas en materia de medio ambiente y clima, un elevado nivel de biodiversidad, la conservación de los recursos naturales y la aplicación de normas exigentes sobre bienestar animal y sobre producción que responden a la demanda, expresada por un creciente número de consumidores, de productos

9 PEÑAS MOYANO, B. «Algunas cuestiones en torno a la denominación de origen como signo distintivo», en Estudios jurídicos de derecho agrario, Ministerio de Agricultura, Pesca y Alimentación, Madrid, 2008, pp. 424 y 425.

10 TOLÓN BECERRA, A. y LASTRA BRAVO, X. «Los alimentos de calidad diferenciada. Una herramienta para el desarrollo rural sostenible», Revista electrónica de Medio Ambiente. UCM, nº. 6, 2009, p. 48. 
obtenidos a partir de sustancias y procesos naturales. Así pues, la producción ecológica desempeña un papel social doble aprovisionando, por un lado, un mercado específico que responde a una demanda de productos ecológicos por parte de los consumidores $y$, por otro, proporcionando al público bienes que contribuyen a la protección del medio ambiente, al bienestar animal y al desarrollo rural. Así se expresa el preámbulo del Reglamento 848/2018, de 30 de mayo de 2018, sobre producción ecológica y etiquetado de los productos ecológicos (Considerando 1). En este sentido, la producción ecológica persigue en el marco de la PAC los mismos objetivos inherentes a todos los regímenes de calidad de los productos agrícolas de la Unión (Considerando 2). La producción ecológica es un sistema que contribuye a la integración de los requisitos de protección del medio ambiente en la PAC y que promueve la producción agraria sostenible (Considerando 4).

En tercer lugar y finalmente, el desarrollo rural persigue el objetivo de lograr un desarrollo territorial equilibrado de las economías y comunidades rurales incluyendo la creación y conservación del empleo.

Según se ha puesto de manifiesto, cuando el legislador ha tomado como objetivo la puesta en valor de los productos agroalimentarios con calidad diferenciada, se está teniendo en cuenta, además de las manifestaciones del patrimonio cultural de un territorio, también la repercusión económica que tiene la calidad agroalimentaria en el desarrollo económico de las zonas rurales. No olvidemos que desde la óptica del productor, la calidad de la producción agroalimentaria es un factor de desarrollo del mundo rural al obtener mayores ingresos como contrapartida del esfuerzo cualitativo que realiza para alcanzar ese plus de calidad agroalimentaria ${ }^{11}$. En efecto, los objetivos específicos que se persiguen con la protección de las denominaciones de origen y de las indicaciones geográficas son asegurar a los agricultores y productores unos ingresos equitativos por las cualidades y las características de un producto determinado o de su método de producción ${ }^{12}$.

Por otra parte, la economía rural puede beneficiarse de la aplicación de regímenes de calidad para los productores que recompensen sus esfuerzos para producir una diversidad de productos de calidad. Tal es particularmente el caso de las zonas menos favorecidas, de las zonas de montaña y de las regiones más remotas, cuyo sector agrario representa una parte significativa de su economía y cuyos costes de producción son elevados. En este sentido, los regímenes de calidad pueden contribuir y servir de complemento tanto a la política de desarrollo rural, como a las políticas de apoyo al mercado y de sostenimiento de la renta que se aplican en el marco de la política agrícola común (PAC). Pueden, en particular, contribuir a las zonas en que el sector agrario reviste la mayor importancia económica, en especial a las zonas desfavorecidas. Así se desprende del preámbulo del Reglamento 1151/2012, de 21 de noviembre de 2012, sobre los regímenes de calidad de los productos agrícolas y alimenticios (Considerando 4). Tales principios programáticos cristalizan después en el artículo 1.1 in fine del propio Reglamento 1151/2012: «Las medidas establecidas en el presente Reglamento pretenden respaldar las actividades agrarias y de transformación y los métodos de producción asociados a los productos de alta calidad, contribuyendo así a la realización de los objetivos de la política de desarrollo rural».

11 SÁNCHEZ HERNÁNDEZ, Á. «Productos agroalimentarios de calidad como mecanismo de protección de productores y de consumidores», Revista Internacional de Doctrina y Jurisprudencia, $\mathrm{n}^{\circ}$. 7, 2014, p. 9.

12 Reglamento 1151/2012, de 21 de noviembre de 2012, sobre los regímenes de calidad de los productos agrícolas y alimenticios (Preámbulo, Considerando 18). 
Sin embargo, tampoco faltan voces que ponen de relieve las posibles desventajas para determinados agricultores situados en las zonas de producción amparadas por un sistema de calidad protegido. Así, una parte de la doctrina sostiene que este proceso puede aumentar la cohesión y sinergia entre los actores del territorio, pero también puede excluir a aquellos que formaban parte del sistema previo de elaboración del producto - ya sea por incapacidad de asumir los costes de transformación o por disconformidad con el nuevo sistema - que, con la nueva legalidad se ven desposeídos del capital simbólico que su producto tenía al ser legalmente monopolizado por el nuevo sello. La creación de una marca de calidad conlleva la creación de un marco institucional y la elaboración de un cuerpo normativo que, a partir de entonces, regulará las características del producto. Una construcción restrictiva a la fuerza, que conllevará la selección de un conjunto de materias primas, manejos y técnicas preexistentes y sus límites territoriales, lo que determinará el conjunto de características consustanciales a la certificación de la nueva marca. Está claro que esta nueva situación limitará usos y manejos tradicionales y generará además nuevas relaciones de poder entre los actores implicados y marcará transiciones y cambios sociales en estos territorios rurales ${ }^{13}$.

\subsection{Implementación de medidas y ayudas de desarrollo rural financiadas por el} FEADER vinculadas a la calidad de la producción agroalimentaria europea

La política de desarrollo rural que implementa el R. 1305/2013, se estructura en torno a la generación y aprobación de programas de desarrollo rural (PDR) a nivel nacional. A tal fin, los Estados miembros podrán presentar bien un programa único para todo su territorio o bien un conjunto de programas regionales que incluyan varias medidas seleccionadas del elenco del R. 1305/2013. Seguidamente, las ayudas financieras del FEADER se canalizarán hacia cada una de las medidas de desarrollo rural que se incorporen en los PDR nacionales.

Efectivamente, el Capítulo I del Título III del R. 1305/2013 incorpora un listado de posibles medidas a adoptar e implementar por los EE.MM. Entre tales medidas se encuentra la referente a los «Regímenes de calidad de los productos agrícolas y alimenticios» (artículo 16) y la que afecta a la «Agricultura ecológica» (artículo 29). Ambas apuestan decididamente por impulsar los sistemas diferenciados de calidad agroalimentaria.

Asimismo, necesariamente cada una de las medidas de desarrollo rural se programará para que contribuya de manera específica a la consecución de una o varias prioridades de desarrollo rural de la UE. El propio R. 1305/2013 dispone en su anexo VI una lista indicativa de las medidas de especial interés para dichas prioridades.

Pues bien, al consultar el indicado anexo VI en particular, resulta que el artículo 16 se considera una medida de especial relevancia para mejorar la competitividad de todos los tipos de agricultura y aumentar la viabilidad de las explotaciones agrarias. Así lo hemos puesto de manifiesto en el epígrafe anterior. Por otra parte, según el mismo anexo VI, el artículo 29 se configura como medida de especial relevancia para restaurar, conservar y mejorar los ecosistemas relacionados con la agricultura y la silvicultura y para mejorar la

13 AGUILAR CRIADO, E., AMAYA CORCHUELO, S. y LÓPEZ MORENO, I. «Alimentos con calidad: Nuevas estrategias rurales para nuevos consumidores», Arxiu d'etnografia de Catalunya: revista d'antropologia social, $\mathrm{n}^{\circ}$. 16, 2016, p. 139. 
eficiencia de los recursos y apoyar el paso a una economía baja en emisiones de carbono y adaptable al cambio climático en los sectores agrario, alimentario y forestal.

Analicemos brevemente el contenido, requisitos y alcance de la medida prevista en el artículo 16 del R. 1305/2015.

En cuanto al ámbito de aplicación objetivo, la medida (y la ayuda financiera aparejada) se aplicará tanto a la introducción como a la consolidación en el seno de una explotación agraria ${ }^{14}$ de alguno de los regímenes de calidad de los productos agrarios y alimenticios legalmente reconocidos en la UE y en los EE.MM.

Concretamente se trata de los siguientes:

\section{A Regímenes específicamente regulados en Reglamentos comunitarios}

a.1. En el Reglamento 1151/2012, sobre los regímenes de calidad de los productos agrícolas y alimenticios. En él se incluyen sistemas productivos vinculados al origen del producto (denominaciones de origen protegidas e indicaciones geográficas protegidas), vinculados al modo de producción y elaboración del producto (especialidades tradicionales garantizadas), y finalmente sistemas que comuniquen características o atributos de los productos agrícolas que aporten valor añadido (términos de calidad facultativos).

a.2. En el Reglamento 848/2018, sobre producción ecológica y etiquetado de los productos ecológicos, vinculado a un específico método de producción.

a.3. En el Reglamento 110/2008, relativo a la indicación geográfica de bebidas espirituosas.

a.4. En el Reglamento 251/2014, sobre la definición, designación, presentación, etiquetado y protección de las indicaciones geográficas, de los productos vitivinícolas aromatizados.

a.5. La parte II, título II, capítulo I, sección 2, del Reglamento 1308/2013, en lo referente al vino.

B Otros regímenes de calidad reconocidos por los Estados miembros, siempre que cumplan determinados criterios relativos al método de producción, a las características y calidad del producto final, a la transparencia del proceso, trazabilidad, etc.

Se podrán incluir regímenes de certificación de las explotaciones agrícolas, de los productos agrarios, del algodón o de los productos alimenticios.

C) Regímenes voluntarios de certificación de productos agrarios reconocidos por los Estados miembros, siempre que cumplan las directrices de la UE sobre las mejores prácticas para el funcionamiento de los regímenes voluntarios de certificación de productos agrarios y alimenticios.

En cuanto al ámbito de aplicación subjetivo del artículo 16, la medida se aplicará a los agricultores y las agrupaciones de agricultores que participen por primera vez o hayan

14 Vid. AMAT LLOMBART, P. «La explotación agraria, sus elementos integrantes y tipos cualificados de explotación. La reforma legislativa pendiente», en Tratado de derecho agrario, Esther Muñiz Espada y Pablo Amat Llombart (Dirs.), La Ley-Wolters Kluver, Madrid, 2017, pp. 157-205. 
participado durante los cinco años anteriores en alguno de los regímenes de calidad objeto de la ayuda, arriba apuntados.

Serán beneficiarios los «agricultores activos», en el sentido del art. 9 del R. $1307 / 2013$ de pagos directos, tal como se aplique en el Estado miembro de que se trate ${ }^{15}$. El concepto alcanza tanto a agricultores personas físicas o jurídicas, como a grupos de personas físicas o jurídicas. En su explotación o superficie agraria deberán al menos llevar a cabo las actividades mínimas definidas por los Estados miembros. Además, podrán demostrar su condición de agricultor activo aportando pruebas de que cumplen alguna de estas condiciones:

a. Que el importe anual de los pagos directos que reciben es al menos del $5 \%$ de los ingresos totales que obtienen a partir de actividades no agrarias en el ejercicio fiscal más reciente;

b. Que sus actividades agrarias no son insignificantes;

c. Que su principal negocio u objeto social de la empresa consiste en ejercer una actividad agraria.

En el ordenamiento interno español, esta cuestión se regula en los artículos 8 a 10 del Real Decreto 1075/2014, de 19 de diciembre, sobre la aplicación a partir de 2015 de los pagos directos a la agricultura y a la ganadería y otros regímenes de ayuda, así como sobre la gestión y control de los pagos directos y de los pagos al desarrollo rural.

En concreto, la norma española añade la opción consistente en aportar pruebas verificables que demuestren que su actividad agraria no es insignificante, sobre la base de que sus ingresos agrarios distintos de los pagos directos supongan el $20 \%$ o más de sus ingresos agrarios totales. E incluso de no cumplir dicha condición, podrán ser considerados «agricultor activo» siempre y cuando se demuestre que ejercen la actividad agraria (en el sentido del artículo 11 del RD. 1074/2014) y asuman el riesgo empresarial de dicha actividad.

Volviendo al estudio del artículo 16 del R. 1305/2013, queda por determinar el alcance específico de la ayuda financiera a conceder a los beneficiarios.

Como ya sabemos, la finalidad de la ayuda es facilitar a los agricultores su participación por primera vez en uno de los regímenes de calidad de los productos agrarios y alimenticios, o bien seguir ayudando a los agricultores que ya hayan participado durante los cinco años anteriores.

Pues bien, la ayuda consistirá en un «incentivo anual», cuyo importe se determinará en función del nivel de los costes fijos ocasionados por la participación en los regímenes subvencionados, durante un período máximo de cinco años.

Y dentro del concepto de «costes fijos» subvencionables, la norma establece tres en concreto: a) los costes ocasionados por la inscripción en un régimen de calidad sub-

15 Para un mayor conocimiento de los tipos de agricultores, vid. CABALLERO LOZANO, J.M. «La empresa agraria. El empresario agrario: concepto y tipología», en Tratado de derecho agrario, Esther Muñiz Espada y Pablo Amat Llombart (Dirs.), La Ley-Wolters Kluver, Madrid, 2017, pp. 105-156. Y también de este mismo autor, «La delimitación del concepto de agricultor en la nueva PAC 2014-2020», en La nueva PAC 2014-2020. Un enfoque desde el derecho agrario, Pablo Amat Llombart y Esther Muñiz Espada (Eds.), Universidad Politécnica de Valencia, Valencia, 2015, pp. 27-56. Asimismo, vid. CAZORLA GONZÁLEZ, M.J. «Protección de la tierra y de los agricultores activos como forma de potenciar el desarrollo rural», Revista de Derecho Agrario y Alimentario, nº. 58, 2011, pp. 13-32. 
vencionado; b) la cuota anual de participación en dicho régimen; c) el coste de los controles necesarios para comprobar el cumplimiento del pliego de condiciones del régimen.

Por otra parte, la ayuda también podrá abarcar los costes derivados de las actividades de información y promoción en el mercado interior, llevadas a cabo por grupos de productores en relación con productos cubiertos por un régimen de calidad subvencionado.

Procede finalmente abordar de manera sucinta el régimen de la ayuda al desarrollo rural vinculada a la «Agricultura ecológica», prevista en el artículo 29 del R. 1305/2015.

Respecto al ámbito subjetivo de aplicación del artículo 29 -en términos similares al artículo 16-, la ayuda se concederá a los agricultores o agrupaciones de agricultores que se comprometan voluntariamente a adoptar o mantener prácticas y métodos de agricultura ecológica definidos en el Reglamento 834/2007 (a partir del 1 de enero de 2021 se aplicará el vigente R. 848/2018, y que deroga al precedente). Serán beneficiarios los «agricultores activos», por lo que en este punto nos remitimos a lo ya señalado al estudiar el art. 16 del R. 1305/2013.

Por lo que afecta al ámbito de aplicación objetivo, la medida se aplicará tanto a la implantación inicial como a la consolidación en el seno de una explotación agraria del método ecológico de gestión agrícola y producción de alimentos.

La producción ecológica se define como el uso de métodos de producción que cumplan lo dispuesto en el Reglamento 848/2018 en todas las etapas de la producción, preparación y distribución, Reglamento que sienta los principios de la producción ecológica y establece las normas aplicables a dicha producción, a la certificación respectiva y al uso de indicaciones referidas a la producción ecológica en el etiquetado y la publicidad, así como a las normas sobre controles adicionales.

La ayuda únicamente se concederá para compromisos que impongan mayores exigencias que: a) las normas obligatorias de condicionalidad exigibles por la normativa comunitaria (arts. 93 y 94 del Reglamento 1306/2013) y nacional (en España aprobadas por el Real Decreto 1078/2014, de 19 de diciembre); b) en relación con la utilización de abonos y productos fitosanitarios, llevar a cabo el mantenimiento de una superficie agraria en un estado adecuado para pasto o cultivo, o bien la realización de una actividad mínima definida por los Estados miembros, en superficies agrarias naturalmente mantenidas en un estado adecuado para pasto o cultivo; c) otros requisitos obligatorios pertinentes establecidos en el derecho nacional.

En cuanto al alcance específico y condiciones de la ayuda financiera a conceder a los beneficiarios de la medida de desarrollo rural, hay que señalar lo siguiente:

a. Los compromisos en virtud de esta medida se contraerán por un período de cinco a siete años, si bien los Estados miembros podrán prever en sus programas de desarrollo rural una prórroga anual una vez finalizado el periodo inicial.

b. La ayuda se concederá anualmente y por hectárea de superficie agrícola.

c. Las ayudas compensarán a los beneficiarios por la totalidad o una parte de los costes adicionales y las pérdidas de ingresos como consecuencia de los compromisos suscritos. 
d. También podrán incluir los costes de transacción hasta un máximo del $20 \%$ de la prima abonada (agricultores individuales) o un $30 \%$ (agrupaciones de agricultores).

\section{RÉGIMEN LEGAL DE LA CALIDAD AGROALIMENTARIA DIFERENCIADA EN ESPAÑA Y SU VINCULACIÓN AL DESARROLLO RURAL Y TERRITORIAL}

\subsection{Calidad alimentaria y calidad diferenciada: distinción}

En España, la calidad agroalimentaria puede ser entendida en un doble sentido, tanto desde la perspectiva de la calidad alimentaria, como desde la calidad diferenciada.

La «calidad alimentaria» supone el conjunto de propiedades y características de un alimento, consecuencia de las exigencias previstas en las disposiciones obligatorias relativas a las materias primas o ingredientes utilizados en su elaboración, a los procesos utilizados en la misma, así como a la composición y presentación del producto final.

Por su parte, por «calidad diferenciada» se entiende el conjunto de características de un producto agrario y alimentario, vinculadas a un origen geográfico o tradición, consecuencia del cumplimiento de requisitos establecidos en disposiciones de carácter voluntario, relativas a sus materias primas o procedimientos de producción, transformación o comercialización ${ }^{16}$.

Así pues, los diferentes regímenes de calidad de productos agrarios y alimenticios a que venimos haciendo referencia en este trabajo, se incluirían bajo la indicada submodalidad de «calidad diferenciada». De hecho, en España merecen especial atención sobre todo los regímenes de calidad vinculados al origen del producto, como las denominaciones de origen protegidas y las indicaciones geográficas protegidas ${ }^{17}$ (destacan las relativas, entre otros, a productos de reconocido prestigio como el vino elaborado en diversas regiones españolas ${ }^{18}$ ). Igualmente la merecen los sistemas de calidad vinculados al modo

16 Ministerio de Agricultura, Pesca y Alimentación. https://www.mapa.gob.es/es/alimentacion/temas/calidadagroalimentaria (Consulta: 14/04/2020). En la doctrina, conviene consultar el trabajo de DE LA CUESTA SÁENZ, J.M. «Notas sobre el concepto de calidad en el Derecho agrario», en Agricultura transgénica y calidad alimentaria: análisis de derecho comparado, coord. por Ana Carretero García, Universidad de Castilla-La Mancha, 2011, pp. 383-393.

17 España se caracteriza por ser un país con gran diversidad cultural e histórica lo cual tiene reflejo en el reconocimiento de un gran número de alimentos con características propias de calidad debidas al ámbito geográfico en que han tenido origen, fundamentalmente, en forma de Denominaciones de Origen Protegidas (DOP) e Indicaciones Geográficas Protegidas (IGP). Así lo señala el Preámbulo (apartado I) de la Ley 6/2015, de 12 de mayo, de Denominaciones de Origen e Indicaciones Geográficas Protegidas de ámbito territorial supraautonómico.

18 Según estadísticas contrastadas, España es el cuarto productor de vino y posee la mayor extensión de viñedo del mundo, con una superficie cultivada de cerca de 1.000 .000 de hectáreas. De esa producción, el $56 \%$ corresponde a vinos de calidad (43\% declarado como vino con Denominación de Origen Protegida (DOP) y 13\% como vino con Indicación Geográfica Protegida (IGP). Se exportan cada año unos once millones de hectolitros de vinos y mostos, y aun así hay grandes excedentes. Los datos vienen proporcionados por el Ministerio de Agricultura, Pesca y Alimentación, que ha dado a conocer las principales cifras de la campaña vitivinícola 2019/2020, extraídas del Sistema de Información de Mercados del Sector Vitivinícola (INFOVI). Y entre la doctrina, para el estudio de la relación entre las DOP vinculadas a la producción del vino y el progreso del desarrollo rural, vid. CEBALLOS MORENO, M. Denominaciones de origen, actividad vitivinícola y desarrollo sostenible de zonas rurales, Tecnos, Madrid, 2017. Ciertamente, a partir de los nuevos enfoques sociales, culturales y ambientales que en la actualidad 
de producción y elaboración del producto (especialidades tradicionales garantizadas) o a un específico método de producción agrario (producción ecológica).

\subsection{Regulación de las DOP y las IGP: incidencia en el desarrollo rural}

El régimen jurídico básico de las DOP y las IGP a nivel de la UE -y por inclusión en España- tiene su punto de referencia actual en el vigente Reglamento 1151/2012, de 21 de noviembre de 2012, sobre los regímenes de calidad de los productos agrícolas y alimenticios. Dicha reglamentación no se aplica a las bebidas espirituosas, a los vinos aromatizados ni a los productos vitícolas, pues estos productos se rigen por su propia legislación comunitaria especializada.

Ello no obstante, la normativa comunitaria sobre DOP e IGP remite a la legislación nacional ciertos aspectos regulatorios sobre la materia, como por ejemplo en el ámbito del control oficial de estos regímenes de calidad (así el control del cumplimiento de los pliegos de condiciones de deben reunir los productos con DOP/IGP, control del uso de las denominaciones y etiquetado en el mercado, etc.). Además, hay otras cuestiones de las que se encarga la legislación nacional: la protección de las DOP e IGP en cuanto derechos de propiedad intelectual, así como la protección de los derechos de los productores y de los consumidores en relación con la información que figure en el etiquetado de los productos amparados por una DOP o IGP, entre otras.

Así las cosas, en España se aprobó la Ley 6/2015, de 12 de mayo, de denominaciones de origen e indicaciones geográficas protegidas de ámbito territorial supraautonómico ${ }^{19}$, la cual reconoce - como no podía ser de otra forma- que los Reglamentos de la Unión Europea serán aplicables con carácter prevalente al contenido de la propia Ley (Disposición adicional quinta). Igualmente, no hay que olvidar la normativa autonómica que seguirá siendo de aplicación a las DOP e IGP que abarquen o se extiendan únicamente al territorio de cada Comunidad autónoma en particular.

La Ley 6/2015 tiene por objeto la aprobación del régimen jurídico complementario al establecido por el Derecho de la Unión Europea, aplicable a las Denominaciones de Origen Protegidas e Indicaciones Geográficas Protegidas cuyo ámbito territorial se extienda a más de una Comunidad autónoma (lo que se denomina ámbito territorial su-

informan la política agraria comunitaria, el autor aborda un estudio jurídico del papel que hoy en día están llamadas a desempeñar las denominaciones de origen vitivinícolas dentro del desarrollo sostenible de las zonas rurales en las que se ubican. De ese modo y fuera de su estricta consideración legal como signos distintivos para la defensa en los mercados de los intereses de los bodegueros y consumidores en base a la garantía de una calidad diferenciada debida al medio geográfico, propone una ampliación de miras públicas de la citada institución con idea de completar su normal vocación comercial con su innegable contribución al logro de la vertebración económica de muchos territorios rurales. Ante el silencio que sobre la materia guarda no solo el legislador sectorial sino la doctrina científica, procede a una revisión de las principales aportaciones que a tal efecto se están realizando no solo desde la Unión Europea a través de la llamada agricultura multifuncional sino desde otros sectores específicos del Derecho administrativo (desarrollo rural, ordenación del territorio, paisaje, turismo), en los que la cuestión planteada está teniendo una importante respuesta. En este sentido, propone un rescate por el ordenamiento público de esos otros valores no comerciales de las denominaciones de origen vitivinícolas (paisaje, cultura, patrimonio etnológico, medio ambiente), que históricamente han estado ligados a los lugares que representan y que van más allá de la clásica mercantilidad de la institución y de su tradicional vinculación a las relaciones jurídico-privadas entre productores y consumidores.

19 Para una primera descripción aproximativa a esta normativa, puede consultarse a MOYA LATORRE, A. «La nueva ley de denominaciones de origen e indicaciones geográficas protegidas», Actualidad Jurídica Iberoamericana, $\mathrm{n}^{\circ}$. 3, 2015, pp. 669-678. 
praautonómico), con especial atención al control oficial antes de la comercialización, delimitando claramente las funciones de las entidades de gestión de las DOP e IGP -Consejos Reguladores-y el ejercicio del control oficial por parte de la autoridad competente (Preámbulo apartado II y art. 1 de la Ley).

No es objeto de este artículo el análisis pormenorizado del contenido de dicha ley, y así, por lo que atiende al interés de este trabajo, esto es la vinculación de las DOP y las IGP al desarrollo rural, debemos destacar lo que señala el apartado I del Preámbulo de la Ley 6/2015: «España se caracteriza por ser un país con gran diversidad cultural e histórica lo cual tiene reflejo en el reconocimiento de un gran número de alimentos con características propias de calidad debidas al ámbito geográfico en que han tenido origen, fundamentalmente en forma de Denominaciones de Origen Protegidas (DOP) e Indicaciones Geográficas Protegidas (IGP). Las DOP e IGP pueden ser consideradas como un elemento que favorece la diferenciación de la producción contribuyendo al incremento de la competitividad de las industrias agroalimentarias, fundamentalmente a través de la valorización de estos productos por parte del consumidor, siendo, al mismo tiempo, un instrumento vertebrador en el desarrollo y sostenibilidad de los tejidos rurales y erigiéndose como una seña de promoción de la imagen de los productos españoles en el exterior».

Como venimos destacando, la mejora en el desarrollo de los territorios rurales puede ir de la mano del fomento de regímenes de calidad de productos agroalimentarios, entre los que destacan sobremanera en España las producciones jurídicamente protegidas mediante una DO o una IG.

En efecto, según se afirma, el llamado desarrollo territorial rural (DTR) surge en las últimas décadas como alternativa al modelo de desarrollo que privilegia la perspectiva económica por encima de cualquier otra. Este aporta la problemática del territorio y pone el foco de interés en la relación entre los agentes y su territorio, en el que formulan y realizan sus proyectos de desarrollo. Se asocia a su vez a otros conceptos como identidad, gobernanza, partenariado o acción colectiva, entendiendo que es un concepto de carácter fundamentalmente sociopolítico y no exclusivamente económico. En el contexto del DTR, las Denominaciones de Origen, por sus características, pueden servir de herramienta para el desarrollo territorial en tanto que tienen como objetivo la transformación productiva desde un modelo que busca anclar la producción al territorio, logrando la territorialización de un recurso local específico. Una DO implica la existencia de un recurso único, no imitable y vinculado a una localidad específica. Esa diferenciación se relaciona no sólo con el producto en sí, también con elementos del territorio en el que es producido, como su paisaje, su cultura, su patrimonio histórico, su saber-hacer, etc. Desde esta perspectiva, las DO entran en el Desarrollo Territorial Rural a través de dos procesos complementarios: permiten la calificación del producto local; pero también permiten la creación de dinámicas y la puesta en valor del propio territorio. La transformación productiva debe venir acompañada de una transformación institucional que propicie la buena gobernanza y con ello la valorización del territorio en su conjunto, desde el establecimiento de un marco jurídico eficaz, la promoción de actuaciones de apoyo a estas figuras hasta la creación de redes. Es ahí donde DTR, DO y gobernanza se alían ${ }^{20}$.

20 FREITAS CAETANO, S. y DEL CANTO FRESNO, C. «Desarrollo territorial, gobernanza y Denominaciones de Origen: el estudio de las «Dos» vitivinícolas de Méntrida, Mondéjar y Uclés», Anales de Geografía de la Universidad Complutense, vol. 34, nº. 2, 2014, p. 67. 
Por nuestra parte, podemos claramente afirmar que la adecuada implantación y exitosa consolidación de un régimen de certificación de calidad de un producto agroalimentario (como la DOP o la IGP) en determinado territorio, permite incrementar los niveles de desarrollo del medio rural en que se implanta. En primer lugar, en el sector primario agrícola, evitando el abandono de la actividad productiva agraria relacionada con el producto protegido por la DO o la IG, reconocido en el mercado y valorado por los consumidores. En segundo lugar, a través del aumento de la rentabilidad económica de dichas explotaciones amparadas por la DO o IG, al tratarse de un producto agroalimentario de calidad que suele venderse a un precio superior que el mismo producto convencional (ej. vino de mesa sin calificación especial frente a un vino de reserva con DO calificada rioja o ribera del Duero, entre otros). Además, ese valor añadido del producto se traslada al resto de la cadena alimentaria (transformación, industrialización, comercialización). Esos beneficios económicos permitirán fijar con más facilidad la población en el medio rural, sobre todo aquella que se dedique a las diferentes fases o etapas productivas y comercializadoras del producto con DO o IG. Y finalmente, todo ello redundará en la mejora de las condiciones de vida de la población agraria y rural que habiten el agro, en dicho territorio en particular.

Sin embargo, como sostiene la doctrina, es imposible hablar de un verdadero proceso de desarrollo territorial sin gobernanza, ya que en la raíz de estos conceptos está la idea de desarrollo integrado, de participación, de construcción de objetivos «desde abajo», de apropiación del proceso de desarrollo por la sociedad civil y de coordinación de actores, condiciones que no se pueden llevar a cabo sin una verdadera articulación entre actores privados y públicos, y sin la distribución equitativa del poder de decisión. La gobernanza se relaciona con las DO en la medida en que la creación de esta figura hace necesario el establecimiento de algunas condiciones básicas que permitan el reconocimiento y el apoyo a la misma, como la creación de un marco jurídico que posibilite el reconocimiento y la protección de los derechos de propiedad colectiva sobre la DO. De la misma manera es importante la puesta en marcha de un conjunto de políticas capaces de apoyar a los actores en las diversas fases de la constitución y puesta en marcha de una DO, de promover relaciones comerciales más equilibradas, de fomentar la creación de redes, de redistribuir el valor a lo largo de la cadena y de promover los valores culturales y la preservación ambiental. En una DO, el papel que pueden desempeñar las instituciones entendidas en su sentido más general, considerando tanto las organizaciones como las reglas tácitas, normas y convenciones presentes en cada territorio- se relaciona con la creación de dinámicas de buena gobernanza local y territorial. Esto ocurre en la medida en que, poniendo en práctica el marco jurídico y las acciones de apoyo a la figura de calidad, son capaces de fomentar las redes de cooperación, la participación local en los procesos decisorios y la colaboración entre actores de diferentes ámbitos, como social, empresarial y gubernamental. Las instituciones de carácter gubernamental se encuentran en una posición privilegiada para fomentar la buena gobernanza dada su visión holística del territorio y las posibilidades que disponen ${ }^{21}$.

Coincidimos básicamente con lo que se apunta. Es más, nos parece que la presencia de un buen hacer agronómico en relación con la producción agroalimentaria, de unas

21 FREITAS CAETANO, S. y DEL CANTO FRESNO, C. «Desarrollo territorial, gobernanza y Denominaciones de Origen: el estudio de las «D.O.s.» vitivinícolas de Méntrida, Mondéjar y Uclés», Anales de Geografía de la Universidad Complutense, vol. 34, no . 2, 2014, pp. 68 y 69. 
artes o métodos tradicionales o especiales y autóctonos, que dotan al producto de esa calidad final, no son suficientes para alcanzar el éxito de la obtención, elaboración, visibilidad, prestigio y adecuada comercialización del producto amparado bajo una DO o una IG.

En el ámbito de la gobernanza resulta imprescindible la regulación jurídica del régimen de calidad protegido. Esto ya sucede desde hace décadas a nivel comunitario, estatal y autonómico, con la peculiaridad de que en España ese régimen legal se centró desde sus orígenes sobre todo en la regulación de la calidad diferenciada de los vinos, para después resultar aplicable a otros tipos de productos alimentarios de renombrada calidad y reconocido prestigio nacional e internacional (jamón ibérico, quesos, productos de huerta, cítricos, horchata...). Ciertamente, el establecimiento de un régimen legal sobre DOP/IGP tiene como objeto -y así lo ratifica la Ley 6/2015- regular la titularidad, el uso, la gestión y la protección de las DOP e IGP vinculadas a un origen territorial, el régimen jurídico aplicable a su control, así como garantizar la protección de las DOP e IGP como derechos de propiedad intelectual, y en fin, proteger los derechos de los productores y de los consumidores (art. 2).

Pero además de un adecuado y eficaz sistema jurídico, también resulta muy necesario poner en juego la política de fomento y auxilio de esta especial forma de producción agrícola de calidad diferenciada. Habida cuenta de los potenciales beneficios de índole territorial, económica, social e incluso ambiental que puede generar el desarrollo de un sistema de calidad de productos agroalimentarios, se entiende imprescindible articular mecanismos de apoyo financieros y materiales para su implantación y sostenimiento. Tal es el fin de las ayudas al desarrollo rural de la PAC establecidas en la UE, entre las que se encuentran las ayudas a los «Regímenes de calidad de los productos agrícolas y alimenticios» -ya analizadas-, establecidas en el artículo 16 del R. 1305/2013 así como en los programas de desarrollo rural nacionales o regionales de los EE.MM. (en España, PDR autonómicos).

Por poner un ejemplo en particular, podemos traer a colación el fomento y la promoción de uno de los «productos estrella» en España como es el vino, sobre todo los vinos de calidad diferenciada y reconocida. Ya en la Ley 24/2003, de 10 de julio, de la viña y del vino se estableció un sistema de protección del origen y la calidad de los vinos (en su Título II, hoy derogado y sustituido por la Ley 6/2015). Pese al tiempo transcurrido, en esta ley ha quedado en vigor el artículo 4, específicamente dedicado a la «Promoción», el cual dispone: «La Administración General del Estado podrá financiar campañas de información, difusión y promoción del viñedo, del vino y de los mostos de uva, en el marco de la normativa de la Unión Europea y de acuerdo con el ordenamiento jurídico nacional vigente». Y así, entre los criterios orientativos que debían seguirse en las campañas financiadas con fondos públicos estatales, se incluían algunos directamente ligados al desarrollo rural: fomentar el desarrollo sostenible del cultivo de la vid, favoreciendo el respeto del medio ambiente, así como la fijación de la población en el medio rural; destacar los aspectos históricos, tradicionales y culturales de los vinos españoles; etc.

Pues bien, entre los programas nacionales de apoyo al vino español, actualmente se encuentra en vigor el Programa 2019-2023, conocido en España como «Programa de Apoyo al Sector Vitivinícola Español» (PASVE), también cofinanciado por la UE. En el mismo, entre otras medidas, se apoya la promoción de vinos en mercados de terceros países, y los vinos que pueden beneficiarse de esta ayuda son aquellos con Denominación de 
Origen Protegida, con Indicación Geográfica Protegida o aquellos en los que se indique la variedad de uva de vinificación.

En otro orden de cosas, la consolidación de la DO puede impulsar otros procesos añadidos a los descritos que son también de una gran importancia para los territorios en los que se asienta una Denominación de Origen. Estos procesos complementarios se pueden englobar en el término de gobernanza territorial, un concepto que relaciona la gobernanza a la idea del territorio como un recurso a ser movilizado, como un activo específico que puede generar beneficios colectivos o externalidades positivas. Bajo este enfoque, la gobernanza se relaciona a una red socio-institucional que abarca tanto actores locales y directamente vinculados a la actividad productiva de la DO, como actores externos y de instituciones de diferentes ámbitos territoriales. Esta red puede ser capaz, a través de actuaciones colectivas y complementarias, de generar un beneficio para el territorio en su totalidad, incluyendo no sólo las actividades de la elaboración del producto con la etiqueta DO, sino los demás aspectos como el patrimonio histórico, cultural, natural y paisajístico de la zona, dinamizando y expandiendo los beneficios a otros sectores de la actividad económica, como el turismo, la hostelería, la gastronomía, etc., propiciando con ello la puesta en valor del territorio en su conjunto ${ }^{22}$.

En relación a esto último, cabe afirmar que en lo que afecta al sector primario agrícola tiene una íntima vinculación con lo que se conoce como «agricultura multifuncional» o como «multifuncionalidad de la agricultura». En ese sentido, la agricultura multifuncional produce bienes tanto privados (alimento, materias primas de origen agrícola o turismo rural) como públicos, los cuales se dividen en sociales (contribución a la viabilidad de las áreas rurales desfavorecidas, la protección de valores culturales y patrimoniales asociados al medio rural o la protección ante el despoblamiento rural) y ambientales (protección de valores paisajísticos, fomento de la biodiversidad y la reducción de los procesos erosivos del suelo) ${ }^{23}$.

En definitiva, y ya para cerrar este epígrafe, no albergamos duda alguna sobre la conexión entre la exitosa implementación de DOP o IGP agroalimentarias en determinado territorio y la mejora del desarrollo rural del mismo. Las mejoras son apreciables tanto a nivel productivo-económico (valor añadido del producto final, buena consideración por el consumidor), a nivel empresarial (viabilidad de explotaciones agrarias e industrias agroalimentarias), a nivel territorial-poblacional (fijación de población rural), como a nivel social (vitalidad del tejido social, asociacionismo, redes...) y medioambiental (buenas prácticas agronómicas y sostenibles).

\subsection{Regulación de la producción ecológica: gestión sostenible de los recursos na- turales y acción por el clima}

En el ámbito de la normativa comunitaria - según ya hemos visto- la producción ecológica se define como aquel sistema general de gestión agrícola y de producción de alimentos que combina las mejores prácticas en materia de medio ambiente y clima, un

22 FREITAS CAETANO, S. y DEL CANTO FRESNO, C. «Desarrollo territorial, gobernanza y Denominaciones de Origen: el estudio de las «D.O.s.» vitivinícolas de Méntrida, Mondéjar y Uclés», cit., p. 70.

23 Así RICART CASADEVALL, S. «La multifuncionalidad de la agricultura: oportunidades y retos», Iagua. www. iagua.es/blogs/sandra-ricart/multifuncionalidad-agricultura-oportunidades-y-retos (Consulta: 18-04-2020). 
elevado nivel de biodiversidad, la conservación de los recursos naturales y la aplicación de normas exigentes sobre bienestar animal y sobre producción que responden a la demanda, expresada por un creciente número de consumidores, de productos obtenidos a partir de sustancias y procesos naturales. Así pues, la producción ecológica desempeña un papel social doble, aprovisionando, por un lado, un mercado específico que responde a una demanda de productos ecológicos por parte de los consumidores y, por otro, proporcionando al público bienes que contribuyen a la protección del medio ambiente, al bienestar animal y al desarrollo rural. De esta forma se manifiesta el Considerando 1 del Reglamento 848/2018, de 30 de mayo de 2018, sobre producción ecológica y etiquetado de los productos ecológicos, el cual ya se encuentra en vigor pero que resultará aplicable a partir del 1 de enero de 2021, por lo que hasta dicha fecha seguirá aplicándose el R. $834 / 2007$ de manera transitoria.

La producción ecológica constituye uno más de los regímenes de calidad de productos agrícolas de la UE, junto con las denominaciones de origen, las indicaciones geográficas y las especialidades tradicionales garantizadas, por lo que en el marco de la PAC persigue los mismos objetivos inherentes a todos los regímenes de calidad de la producción agroalimentaria europea, entre ellos la mejora y el progreso de los territorios rurales mediante el impulso al desarrollo rural. En especial, se aprecia una intensa y directa relación entre el método de producción ecológico y la consecución del segundo objetivo general del desarrollo rural, esto es, aquel que se propone «garantizar la gestión sostenible de los recursos naturales y la acción por el clima» (art. 4.b) del R. 1305/2015).

A su vez, dicho objetivo general, por un lado, queda enmarcado en la prioridad número cuatro del desarrollo rural, prevista en el mismo Reglamento 1305/2013: «Restaurar, preservar y mejorar los ecosistemas relacionados con la agricultura y la silvicultura». Dicha prioridad se desglosa en tres sub-prioridades, a saber: a) Restaurar, preservar y mejorar la biodiversidad (incluidas las zonas Natura 2000 y las zonas con limitaciones naturales u otras limitaciones específicas), los sistemas agrarios de alto valor natural, así como el estado de los paisajes europeos; b) Mejorar la gestión del agua, incluyendo la gestión de los fertilizantes y de los plaguicidas; c) Prevenir la erosión de los suelos y mejorar la gestión de los mismos. Y por otro lado, el citado objetivo conecta también con la prioridad número cinco: «Promover la eficiencia de los recursos y fomentar el paso a una economía baja en carbono y capaz de adaptarse al cambio climático en los sectores agrario, alimentario y forestal». Tales prioridades se recogen en el artículo 5 del R. 1305/2015.

Por consiguiente, la producción ecológica, como régimen diferenciado y certificado de calidad agroalimentaria, por su propia naturaleza en cuanto método de producción altamente respetuoso con el medio ambiente y los recursos naturales, se convierte en uno de los sistemas agronómicos de producción de alimentos más vinculados al objetivo ambientalista y de sostenibilidad del desarrollo rural en los territorios donde se implanta, precisamente al preconizar una producción agraria sostenible desde la perspectiva ambiental, socio-económica y territorial.

En lo que concierne a la regulación jurídica de este régimen de calidad agroalimentaria diferenciada (Reglamento 848/2018 de la UE), se encarga ante todo de establecer los principios de la producción ecológica y las normas aplicables a dicha producción, principios y normas a los que se deberán ajustar los operadores y explotaciones agrarias que se 
califiquen de ecológicas. Dichas normas se extenderán, además de a la fase de obtención del producto, a las posteriores etapas de recogida, envasado, transporte y almacenamiento de los productos ecológicos. En suma, afecta a su producción, preparación-tratamiento y distribución. También regula el sistema específico de «certificación del producto final», procedimiento necesario e imprescindible previo a la comercialización de cualquier producto calificado y etiquetado como «ecológico». Igualmente se establecen disposiciones específicas sobre el uso de indicaciones y términos referidos a la producción ecológica en el etiquetado y la publicidad de los productos destinados al consumo, incluido el logotipo de producción ecológica. Finalmente, contiene normativa aplicable a los controles oficiales sobre la producción ecológica. No podemos detenernos, obviamente, en el estudio de este régimen jurídico.

Respecto a la situación del sector de la producción ecológica a nivel macro, en el ámbito nacional -según apunta el Ministerio de Agricultura, Pesca y AlimentaciónEspaña, con cerca de 2.300.000 hectáreas cultivadas en 2018, ocupa el primer lugar en superficie de agricultura ecológica de la UE y el cuarto a nivel mundial. En cuanto a las explotaciones ganaderas ecológicas, se mantiene un crecimiento global discreto pero continuo, y respecto a las industrias ecológicas se aprecia un avance importante ${ }^{24}$.

Desde la perspectiva institucional, en España, las autoridades competentes de las Comunidades Autónomas son las responsables principales de la implementación de la regulación comunitaria sobre producción ecológica, certificación de la producción, etiquetado y control oficial (lo que implica la organización y supervisión del programa de control de la producción ecológica), realizando también otras funciones asignadas en la reglamentación europea.

A partir de esta perspectiva jurídica y de distribución competencial, a nivel estatal cabe citar el Real Decreto 833/2014, de 3 de octubre, por el que se establece y regula el Registro General de Operadores Ecológicos y se crea la Mesa de coordinación de la producción ecológica. Esta norma derogó el Real Decreto 1852/1993, de 22 de octubre, sobre producción agrícola ecológica y su indicación en los productos agrarios y alimenticios y por el que se establecieron las funciones y composición de la Comisión Reguladora de la Agricultura Ecológica. Hoy día, la utilidad y necesidad de una Mesa de coordinación de la producción ecológica, se revela en cuanto órgano de coordinación entre el Estado central (a través del Ministerio de Agricultura) y las autoridades competentes de las Comunidades autónomas en materia de producción ecológica, además de desempeñar las funciones de asesoramiento y coordinación que se le encomienden.

Evidentemente, el análisis en profundidad del régimen jurídico comunitario y nacional aplicable a la producción ecológica excede y escapa al objeto de este estudio ${ }^{25}$.

Así nuestra intención es simplemente poner de relieve la intrínseca vinculación del método ecológico de producción agroalimentaria con el desarrollo rural del territorio

24 Informe del MAPA. Avance de datos «Agricultura Ecológica 2018». 19-08-2019. www.mapa.gob.es/es/prensa/ ultimas-noticias. (Consulta: 24-04-2020).

25 Para mayor conocimiento sobre la materia, consúltese el interesante trabajo de CABALLERO LOZANO, J.M. «Régimen de la producción ecológica de vinos. Aportación al «Derecho de la agricultura ecológica en España», Revista de Derecho Agrario y Alimentario, nº. 70, 2017, pp. 37-82. 
donde se implanta, prestando especial atención al objetivo ambientalista y de sostenibilidad que debe caracterizar al desarrollo rural ${ }^{26}$.

En ese sentido, la doctrina ha puesto de manifiesto las bondades que aporta la agricultura ecológica (AE) en beneficio de un desarrollo rural sostenible.

En el contexto del desarrollo rural sostenible, ninguna forma de manejo de los sistemas productivos se acerca tanto como la agricultura y ganadería ecológica a la hora de satisfacer el amplio rango de objetivos que pretende alcanzar la política de desarrollo rural:

La AE mejora la competitividad de la agricultura. La producción ecológica posibilita producir y comercializar productos certificados, diferenciados por su calidad, su mejora ambiental y su impacto social beneficioso y de alto valor añadido; permite diversificar ofertas con lo que se diversifican la economía local y fomenta al turismo comprometido con el desarrollo rural.

La AE tiene mayores beneficios ambientales. La gestión ecológica consigue altos niveles de biodiversidad, reduce la contaminación por agroquímicos, mejora la fertilidad de los suelos y reduce el gasto energético y las emisiones de gases con efecto invernadero. Permite el mantenimiento de la actividad agraria en zonas más vulnerables y en espacios naturales de alto valor ecológico. Contribuye a cerrar los ciclos de la materia y está basada en prácticas extensivas.

La AE ayuda a mejorar la economía rural y la calidad de vida rural. Los estudios realizados en Europa muestran que la AE genera alrededor de un $30 \%$ más de empleo que las fincas no ecológicas. Frente al envejecimiento y la huida del campo, la producción y la industria ecológica atraen a la gente joven, más emprendedora, con mayor formación y además tiene una propuesta clara a favor de la mujer; todo esto posibilita el mantenimiento de la población en su medio y la vertebración del territorio. El mayor engranaje en el mercado local ayuda a retener el dinero en la economía local ${ }^{27}$.

Y en la misma línea, se afirma que la agricultura ecológica es un sistema holístico de manejo de la producción que aumenta la salud del agroecosistema, haciendo uso tanto de conocimiento tradicional como de conocimiento científico. Los sistemas de agricultura ecológica se basan más en el manejo de los ecosistemas que en el uso de insumos agrícolas externos. El desarrollo rural está dirigido a mejorar la calidad de vida de las comunidades rurales por medio de la satisfacción de sus aspiraciones socioeconómicas y culturales y el fortalecimiento de su organización social, al mismo tiempo que protege los recursos naturales.

La agricultura ecológica, gracias a su enfoque holístico, contribuye al desarrollo rural de las siguientes formas:

a. Mejora la gobernanza. Coloca al productor en el centro de la estrategia de producción agrícola restableciendo la función de toma de decisiones de las comunidades locales, garantizando su derecho a controlar sus propios recur-

26 Vid. AMAT LLOMBART, P. «Recepción del principio de desarrollo sostenible en la legislación española e implicaciones para la protección del medio ambiente y el sector agroalimentario», en I diritti della terra e del mercato agroalimentare. Liber amicorum Alberto Germanò, Utet, Turín, 2016, pp. 550-584.

27 LABRADOR MORENO, J.C. «Un ejemplo de coherencia: la producción ecológica y el desarrollo rural sostenible», Actualidad Leader. Revista de desarrollo rural, $\mathrm{n}^{\circ} .38,2007$, p.10. 
sos y dedicando su participación activa en una cadena alimentaria de valor agregado.

b. Crea un espacio económico dinámico. Al reducir la mecanización y evitar el uso de agroquímicos, crea puestos de trabajo y aumenta los retornos de la mano de obra. La producción diversificada de productos de calidad disminuye los impactos de las malas cosechas y aumenta las oportunidades de comercialización. La diversidad es el medio para alcanzar la seguridad de ingresos y alimentaria.

c. Mantiene un ambiente saludable. Por medio de su enfoque ecológico, mantiene la integridad del ecosistema y la productividad de los recursos naturales. Conserva los paisajes naturales y las especies silvestres, devuelve la vitalidad a los suelos y mantiene la biodiversidad por medio del uso y desarrollo de semillas locales. Al reducir el uso de insumos agroquímicos, la agricultura ecológica proporciona un ambiente de trabajo más saludable para los productores.

d. Edifica el capital social de las áreas rurales. La agricultura ecológica se caracteriza más por la intensidad de conocimiento que por la intensidad de capital o de recursos; por lo tanto, hace uso del conocimiento tradicional y promueve el intercambio campesino a campesino. Proporciona las herramientas necesarias para la inspección y el control, tal es el caso de los Sistemas de Control Interno y de Garantía Participativos que fortalecen la organización social y empoderan a las comunidades rurales.

En definitiva, la agricultura ecológica es un modelo para el desarrollo rural. La agricultura ecológica está demostrando con ejemplos de la vida real cómo aumentar la sostenibilidad económica, social y ambiental. No solamente las poblaciones rurales gozan de los resultados de la agricultura ecológica, también los habitantes urbanos están en una mejor situación. Por lo tanto, los gobiernos a nivel local y nacional deberían utilizar la agricultura ecológica como una estrategia para el desarrollo rural, involucrando a las comunidades y a los consumidores en sus decisiones. Las autoridades locales pueden crear condiciones positivas para el desarrollo de la agricultura ecológica en sus regiones ${ }^{28}$.

\section{CONCLUSIONES}

El desarrollo rural, en cuanto política y en cuanto objetivo territorial de las zonas rurales europeas, está principalmente dirigido a mejorar la calidad de vida de la población y de las comunidades rurales. A tal fin se procurar dar una adecuada satisfacción a sus aspiraciones económicas, sociales y culturales, fortaleciendo a la vez su organización social. Por otra parte, el desarrollo rural pretende al mismo tiempo proteger y mejorar los recursos naturales, paisajísticos y medioambientales presentes en el territorio rural.

Entre las actividades económicas más relevantes que se desarrollan en las zonas rurales se halla la agricultura y ganadería. Determinadas producciones agroalimentarias

28 IFOAM. International Federation of Organic Agriculture Movements. Agricultura ecológica y desarrollo rural. www.ifoam-eu.org/sites/default/files/page/files/rural_development_es.pdf. (Consulta: 24-04-2020). 
se han hecho merecedoras de un reconocimiento y calidad vinculados al origen geográfico y al método de producción. Jurídicamente han sido aprobadas normativas que regulan y protegen dichos sistemas de calidad de productos agrarios y alimenticios, tanto a nivel comunitario como español.

El estudio y análisis de la relación existente entre la implantación exitosa de regímenes de calidad agroalimentaria en determinados territorios y el progreso del desarrollo rural de los mismos, arroja un balance positivo. En suma, la implantación de sistemas jurídicos y agronómicos de reconocimiento de la calidad de productos agroalimentarios en un territorio determinado, incide plenamente en la consecución de los objetivos políticos del desarrollo rural a nivel de la UE y en España.

La política comunitaria de desarrollo rural se encuentra ubicada dentro de una política más general, la Política Agrícola Común, conformando el segundo pilar de la misma. Los objetivos esenciales del desarrollo rural europeo, abogan por un desarrollo territorial equilibrado y sostenible, que a su vez exige necesariamente fomentar un sector agrario competitivo e innovador al tiempo que respetuoso con el medio ambiente, los recursos naturales y el clima.

Ciertamente el desarrollo rural cuenta con apoyo financiero para impulsar medidas concretas en pro de la consecución de tales objetivos. Entre tales medidas se encuentra la dirigida a fomentar e implantar en el seno de explotaciones agrarias, dirigidas por agricultores activos, regímenes de calidad de productos agrícolas y alimenticios, destacando sobremanera las DO, las IGP y la producción ecológica. En efecto, el R. 1305/2013 contiene preceptos (arts. 16 y 29) específicamente encomendados a tal fin. Se trata de promover la implantación de tales regímenes de calidad agroalimentaria diferenciada y apoyar su sostenimiento en el tiempo, financiando los costes de instalación, de adaptación al nuevo sistema productivo, de formación, de promoción, etc. La financiación se articula mediante los programas estatales de desarrollo rural implantados a nivel nacional.

La implantación de regímenes de calidad agroalimentarios puede coadyuvar al objetivo del desarrollo rural de aumentar la competitividad de la agricultura. Ante todo, el producto amparado por una DOP, una IGP o bien certificado como procedente de la agricultura ecológica, posee un valor añadido intrínseco, un prestigio derivado de su específico modo de producción y de su origen geográfico, que le aporta una notable consideración en el mercado y entre los consumidores finales. Estos aprecian y valoran la calidad del producto en sí, lo cual puede incidir favorablemente en la elección o preferencia de compra. Tal diferenciación de otros productos convencionales unido a la demanda existente, favorece la apreciación del producto de calidad y con ello su mayor precio final que el consumidor está dispuesto a pagar en atención a las bondades que atesora. El precio superior del producto de calidad redunda en beneficio de la cadena alimentaria, incluyendo mejores rendimientos para los agricultores, que podrían evitar el abandono de explotaciones por falta de beneficios. En definitiva, el valor añadido del producto se traslada al resto de eslabones de la cadena alimentaria (transformación, industrialización, comercialización). Los beneficios son apreciables en el nivel productivo-económico (valor añadido del producto final, buena consideración por el consumidor) y en el nivel empresarial (viabilidad y rentabilidad de explotaciones agrarias e industrias agroalimentarias). Asimismo, el éxito y prestigio en el mercado de un producto agroalimentario de calidad puede facilitar la diversificación de la actividad económica en el medio rural, extensible por ejemplo 
a sectores como la gastronomía o el turismo rural vinculados a la cultura, al territorio y al disfrute de los valores que se agrupan en torno al producto certificado de calidad.

Por otra parte, la consolidación de regímenes de calidad agroalimentarios en general, y en particular aquellos más ligados a la protección del medio ambiente (como la producción ecológica o integrada), puede claramente ayudar al objetivo del desarrollo rural consistente en lograr la sostenibilidad medioambiental, la gestión sostenible de los recursos naturales y las acciones en favor de la lucha contra el cambio climático. En efecto, el sello de calidad agroalimentaria tiene mucho que ver con la obtención de un producto que destaque por sus condiciones excepcionales, por el mimo invertido en el proceso de elaboración, y no tanto por su producción en masa. Esto entronca con un sistema productivo amigable con el medio ambiente, con el correcto y razonable uso de los insumos, con la apuesta por la protección de los recursos naturales. Ciertamente, la agricultura de calidad certificada se asocia con buenas prácticas agrícolas y medioambientales: en relación con el suelo y la tierra (menos productos químicos, suelos más fértiles y menos contaminados), con el agua (ahorro en recursos hídricos, menos contaminación de acuíferos, por ejemplo con nitratos), con el aire (reducción de la emisión de gases de efecto invernadero, efecto de captación o sumidero de carbono), con la biodiversidad (favoreciendo los ecosistemas vinculados a la agricultura, las especies silvestres), con los paisajes (manteniendo la cubierta verde, silvicultura sostenible), con el clima (mejor adaptación al cambio climático, mitigación del mismo), con la energía (uso de energías limpias y renovables, menor mecanización y uso de combustible), etc. En esa línea, la producción ecológica, en atención a su propia naturaleza en cuanto método de producción altamente respetuoso con el medio ambiente y los recursos naturales, se convierte en uno de los sistemas agronómicos de producción de alimentos más vinculados al objetivo ambientalista y de sostenibilidad del desarrollo rural en los territorios donde se implanta, precisamente al preconizar una producción agraria sostenible desde la perspectiva ambiental, socio-económica y territorial.

Finalmente, el apoyo institucional y financiero a los sistemas de calidad certificada de productos agroalimentarios, puede colaborar con la consecución del objetivo del desarrollo rural consistente en alcanzar un desarrollo territorial equilibrado de las economías y comunidades rurales. Ante todo, en aras de procurar una adecuada vertebración de los territorios rurales, resulta necesario facilitar e incentivar el asentamiento permanente de la población en las zonas rurales. Es bien sabido que la fijación de habitantes al territorio rural constituye un problema y un grave desafío actual (no solo en Europa, pues basta recordar en nuestro país las grandes zonas deshabitadas de la llamada «España vaciada»). Pues bien, para lograr fijar población en el medio rural la condición indispensable radica en que las comunidades rurales puedan disfrutar de condiciones de vida, de trabajo y de bienestar lo suficientemente dignas como para resultar atractivo su permanencia en el territorio. Y a tal fin el sector agrario y la agricultura de calidad certificada pueden ayudar, generando explotaciones agrarias rentables y viables, oportunidades de negocio, reactivando la economía rural, creando empleo, así como atrayendo a jóvenes y a mujeres al medio rural.

Ahora bien, llegados a este punto hay que concluir que el éxito de la implantación de un régimen de calidad para determinadas producciones agrarias o alimentarias (DOP, IGP, producción ecológica...), en los tiempos actuales no solo depende de la disponibi- 
lidad de buenas materias primas obtenidas del terreno, ni de unas condiciones geográficas, climatológicas, conocimientos o técnicas particulares, ni del empleo de unas buenas prácticas agronómicas o métodos tradicionales de elaboración del producto anclados al territorio y a saberes endógenos.

Siendo tales elementos muy necesarios, sin embargo, hace falta la concurrencia de otras condiciones legales e institucionales que consoliden los sistemas de calidad. Nos referimos, en primer término, a la adecuada y eficaz regulación jurídica del régimen de calidad agroalimentaria protegido, que regule la cadena de producción y facilite los controles oficiales de la misma. El marco jurídico debe posibilitar al agricultor y al productor el justo reconocimiento y protección de los derechos de propiedad colectiva, de marca, de calidad diferenciada, de etiquetado distintivo que a la postre visibilice y ponga de manifiesto la calidad del producto final en el mercado y ante los consumidores. Y en segundo término, también resulta necesario el correcto funcionamiento institucional de los organismos públicos y privados encargados de gestionar los regímenes de calidad (por ejemplo, los Consejos reguladores de las DOP), facilitando la adecuada administración, manejo y promoción de las producciones agroalimentarias de calidad diferenciada. De la misma manera, y finalmente, resulta imprescindible hacer efectiva una política de fomento y promoción de estas especiales fórmulas de producción agrícola de calidad, articulando y dotando suficientemente mecanismos de apoyo financiero y material a los actores implicados en la puesta en marcha y la continuidad del nuevo sistema productivo. Con dicha finalidad se establecen y financian determinadas medidas de desarrollo rural del segundo pilar de la PAC: las ayudas a los regímenes de calidad de los productos agrícolas y alimenticios previstas en el Reglamento 1305/2013, incardinadas a nivel nacional en los programas de desarrollo rural aprobados por los Estados miembros de la UE.

En suma y ya para concluir, los espacios rurales están llamados a desempeñar una diversidad de funciones en pro del bien común. Como se ha visto en los tiempos de crisis que nos ha tocado vivir, el medio rural y el sector agrario constituyen una garantía de la seguridad alimentaria y del abastecimiento de productos de consumo básicos y esenciales para la población. Los consumidores demandan a este sector productos variados, suficientes pero también de calidad (más naturales, más ecológicos, más saludables...). El sector agroalimentario puede responder a dicha demanda mediante la implantación de sistemas productivos que certifican la calidad del producto final y lo identifican suficientemente en el comercio. La buena acogida de estas producciones puede suponer una excelente oportunidad para la revitalización del campo, para la reactivación de economías rurales maltrechas y deprimidas, para el desarrollo de explotaciones agrarias situadas en zonas con fragilidad medioambiental. En definitiva, todo ello puede y debe comportar un decidido impulso al desarrollo rural de los territorios implicados, que redunde en beneficio de las comunidades rurales que los habitan y los mantienen vivos, así como en beneficio de la sociedad en su conjunto.

\section{BIBLIOGRAFÍA}

Aguilar Criado, E., Amaya Corchuelo, S. y López Moreno, I. «Alimentos con calidad: Nuevas estrategias rurales para nuevos consumidores», Arxiu d'etnografia de Catalunya: revista d'antropologia social, $\mathrm{n}^{\mathrm{o}}$. 16, 2016, pp. 137-152. 
Amat Llombart, P. «Indicaciones de calidad en productos agrícolas y alimenticios e intereses de los consumidores», en Le indicazioni di qualità degli alimenti. Diritto internazionale ed europeo, Giuffrè, Milán, 2009, pp. 100-112.

Amat Llombart, P. «La política y las ayudas al desarrollo rural en la PAC 2014-2020: Proceso de aplicación en España», en La nueva PAC 2014-2020. Un enfoque desde el derecho agrario, Pablo Amat Llombart y Esther Muñiz Espada (Eds.), Universidad Politécnica de Valencia, Valencia, 2015, pp. 177-228.

Amat Llombart, P. «Recepción del principio de desarrollo sostenible en la legislación española e implicaciones para la protección del medio ambiente y el sector agroalimentario», en I diritti della terra e del mercato agroalimentare. Liber amicorum Alberto Germanò, Utet, Turín, 2016, pp. 550-584.

Amat Llombart, P. «O segundo pilar da PAC no horizonte de 2020. Missao, objetivos e prioridades do desenvolvimento rural no ambito do regulamento 1305/2013», en A lei agraria nova, Edit. Juruá, Brasil, 2017, pp. 137-155.

Amat Llombart, P. «La explotación agraria, sus elementos integrantes y tipos cualificados de explotación. La reforma legislativa pendiente», en Tratado de derecho agrario, Esther Muñiz Espada y Pablo Amat Llombart (Dirs.), La Ley-Wolters Kluver, Madrid, 2017, pp. 157-205.

Amat Llombart, P. «Principios jurídicos informadores, orientadores y de aplicación de la Política Agrícola Común Europea 2014-2020», Revista de Derecho Agrario y Alimentario, nº. 72, 2018, pp. 7-30.

Amat Llombart, P. y Monfort Peris, R. El contrato territorial para el desarrollo sostenible del medio rural, Aranzadi, Cizur Menor, 2016.

Caballero Lozano, J. M. «La delimitación del concepto de agricultor en la nueva PAC 2014-2020», en La nueva PAC 2014-2020. Un enfoque desde el derecho agrario, Pablo Amat Llombart y Esther Muñiz Espada (Eds.), Universidad Politécnica de Valencia, Valencia, 2015, pp. 27-56.

Caballero Lozano, J. M. «La empresa agraria. El empresario agrario: concepto y tipología», en Tratado de derecho agrario, Esther Muñiz Espada y Pablo Amat Llombart (Dirs.), La Ley-Wolters Kluver, Madrid, 2017, pp. 105-156.

Caballero Lozano, J. M. «Régimen de la producción ecológica de vinos. Aportación al «Derecho de la agricultura ecológica en España», Revista de Derecho Agrario y Alimentario, nº. 70, 2017, pp. 37-82.

Cazorla González, M. J. «Protección de la tierra y de los agricultores activos como forma de potenciar el desarrollo rural», Revista de Derecho Agrario y Alimentario, nº. 58, 2011, pp. 13-32.

Ceballos Moreno, M. Denominaciones de origen, actividad vitivinícola y desarrollo sostenible de zonas rurales, Tecnos, Madrid, 2017.

De La Cuesta Sáenz, J. M. «Notas sobre el concepto de calidad en el Derecho agrario», en Agricultura transgénica y calidad alimentaria: análisis de derecho comparado, coord. por Ana Carretero García, Universidad de Castilla-La Mancha, 2011, pp. 383-393.

De La Cuesta SÁenz, J. M. «La regulación del desarrollo rural en España», Revista de Derecho Agrario y Alimentario, $\mathrm{n}^{\circ} .72,2018$, pp. 31-47.

Freitas Caetano, S. y Del Canto Fresno, C. «Desarrollo territorial, gobernanza y Denominaciones de Origen: el estudio de las «D.O.s.» vitivinícolas de Méntrida, Mondéjar y Uclés», Anales de Geografía de la Universidad Complutense, vol. 34, nº. 2, 2014, pp. 65-95.

IFOAM. International Federation of Organic Agriculture Movements. Agricultura ecológica y desarrollo rural.www.ifoam-eu.org/sites/default/files/page/files/rural_development_es.pdf

LABrador Moreno, J. C. «Un ejemplo de coherencia: la producción ecológica y el desarrollo rural sostenible», Actualidad Leader. Revista de Desarrollo Rural, n. 38, 2007, pp. 10-11.

Millán SALAS, F. «Los regímenes de calidad de los productos agrícolas y alimenticios tras el Reglamento (UE) 1151/2012», Actualidad Civil, nº 10, 2014.

Millán Salas, F. «Producción agroalimentaria de calidad: denominaciones de origen e indicaciones geográficas protegidas, especialidades tradicionales garantizadas, producción ecológica e integrada», 
en Tratado de derecho agrario, Esther Muñiz Espada y Pablo Amat Llombart (Dirs.), La Ley-Wolters Kluver, Madrid, 2017, pp. 611-655.

Millán Salas, F. «La protección de los signos geográficos de calidad de los productos agroalimentarios a través del Derecho de marcas y de la competencia desleal», en Estudios de Derecho Agrario en Homenaje al profesor D. Ramón Herrera Campos, Dykinson, Madrid, 2020, pp. 161-172.

Ministerio De Agricultura, Pesca y Alimentación. https://www.mapa.gob.es/es/alimentacion/temas/ calidad-agroalimentaria

Ministerio De Agricultura, Pesca y Alimentación. Informe del MAPA. Avance de datos «Agricultura Ecológica 2018». www.mapa.gob.es/es/prensa/ultimas-noticias

MuñIz EsPada, E. Derecho agroalimentario y ciberseguridad, Reus, Madrid, 2019.

MuñIz EsPadA, E. Hacia unas nuevas relaciones entre el Registro Mercantil y la actividad agraria, Centro de Estudios Registrales, Madrid, 2020.

Peñas Moyano, B. «Algunas cuestiones en torno a la denominación de origen como signo distintivo», en Estudios jurídicos de derecho agrario, Ministerio de Agricultura, Pesca y Alimentación, Madrid, 2008.

RicART CASADEvall, S. «La multifuncionalidad de la agricultura: oportunidades y retos», Iagua, 27-042014. www.iagua.es/blogs/sandra-ricart/multifuncionalidad-agricultura-oportunidades-y-retos

RODRÍGUEz CACHÓN, T. Relaciones contractuales de la cadena alimentaria. Estudio desde el análisis económico del Derecho, Dykinson, Madrid, 2020.

SÁnchez HernÁNDEZ, Á. «Productos agroalimentarios de calidad como mecanismo de protección de productores y de consumidores», Revista Internacional de Doctrina y Jurisprudencia, $\mathrm{n}^{\circ}$. 7, 2014.

SÁnchez Hernández, A. «Productos agroalimentarios de calidad y su indicación en España», Campo jurídico. Revista de direito agroambiental e teoria do direito, vol. 3, $\mathrm{n}^{\circ} .1,2015$.

Tolón Becerra, A. y Lastra Bravo, X. «Los alimentos de calidad diferenciada. Una herramienta para el desarrollo rural sostenible», Revista electrónica de medio ambiente. UCM, nº . 6, 2009, pp. 1-67. 